\title{
Spontaneous resolution of idiopathic thoracic spinal cord herniation: case report
}

\author{
Nardin Samuel, MSc, ${ }^{1}$ Christina L. Goldstein, MD, FRCSC, ${ }^{2}$ Carlo Santaguida, MD, ${ }^{3,5}$ and \\ Michael G. Fehlings, MD, $\mathrm{PhD}^{3,4,5}$ \\ ${ }^{1}$ University of Toronto; '2Division of Orthopedic Surgery, University of Toronto; ${ }^{3}$ Division of Neurosurgery, Spinal Program, \\ University of Toronto; ${ }^{4}$ Department of Genetics and Development, Toronto Western Hospital; and ${ }^{5}$ Krembil Neuroscience Centre, \\ University Health Network, Toronto, ON, Canada
}

\begin{abstract}
Spinal cord herniation is a relatively rare but increasingly recognized clinical entity, with fewer than 200 cases reported in the literature to date. The etiology of this condition remains unknown, and surgery is used as the primary treatment to correct the herniation and consequent spinal cord compromise. Some patients without clinical progression have been treated with nonoperative measures, including careful follow-up and symptomatic physical therapy. To date, however, there has been no published report on the resolution of spinal cord herniation without surgical intervention.

The patient in the featured case is a 58-year-old man who presented with mild thoracic myelopathy and imaging findings consistent with idiopathic spinal cord herniation. Surprisingly, updated MRI studies, obtained to better delineate the pathology, showed spontaneous resolution of the herniation. Subsequent MRI 6 months later revealed continued resolution of the previous spinal cord herniation.

This is the first report of spontaneous resolution of a spinal cord herniation in the literature. At present, the treatment of this disorder is individualized, with microsurgical correction used in patients with progressive neurological impairment. The featured case highlights the potential variability in the natural history of this condition and supports considering an initial trial of nonoperative management for patients with mild, nonprogressive neurological deficits.
\end{abstract}

http://thejns.org/doi/abs/10.3171/2014.12.SPINE14950

KEY WORDS idiopathic; spinal cord herniation; case study; nonoperative management; thoracic

$\mathrm{S}$ PINAL cord herniation is relatively rare, with fewer than 200 cases reported in the literature to date. The etiology of this condition remains unknown, and surgery is generally undertaken to correct the herniation and consequent spinal cord compromise. Some patients without clinical progression have been treated with nonoperative measures, including careful follow-up and symptomatic physical therapy. To date, however, there has been no published report on the resolution of spinal cord herniation without surgical intervention. This report details the first case of the resolution of spinal cord herniation without surgical intervention.

\section{Case Report}

History and Examination

A 58-year-old man presented to our clinic for the assessment of radiological findings suggestive of T6-7 spi- nal cord herniation. The patient presented with a 15-month history of pain in the left posterior aspect of the thorax, which improved after approximately 6 months. However, he experienced consistent numbness in the left side of his body and lower extremity, with intermittent paresthesias in the left lower extremity. There was no history of any preceding trauma, and the patient denied any weakness in his leg or any gait dysfunction. He also denied bowel and bladder dysfunction. There were no symptoms on the right side of his body. His medical history was remarkable for hypertension, hypercholesterolemia, acid reflux, and benign prostatic hypertrophy. He had previously undergone procedures for hernia repairs and a hemorrhoidectomy.

On examination, he denied tenderness to palpation over the thoracic spine. No focal motor weakness was detectable. Standard gait, tandem gait, heel walking, and toe walking were all normal. Sensory examination revealed

SUBMITTED September 19, 2014. ACCEPTED December 31, 2014.

INCLUDE WHEN CITING Published online May 29, 2015; DOI: 10.3171/2014.12.SPINE14950.

DISCLOSURE The authors report no conflict of interest concerning the materials or methods used in this study or the findings specified in this paper. 
that he had decreased sensation to light touch and pinprick in the L-1 to S-2 distributions on the left side with normal proprioception at both great toes. He was normoreflexic with a downgoing plantar response bilaterally. Tone was equal bilaterally with no clonus or spasticity.

Magnetic resonance imaging of the thoracic spine performed 1 year prior to his clinic presentation showed evidence of focal anterolateral spinal cord displacement at T6-7 with kinking (Fig. 1A and B) and associated T2 signal change in the cord. There was complete loss of CSF at the site of the anterolateral spinal cord herniation through the dura mater. A follow-up scan obtained 1 month before his initial clinic visit remarkably demonstrated complete resolution of the spinal cord kinking (Fig. 1C and D). The cord continued to abut the anterior aspect of the dura; however, there was no further protrusion outside of the dura. There appeared to be an epidural collection of CSF, which may signify an ongoing breach in the dura. The patient continued to experience sensory symptoms that could be attributed to the initial spinal cord herniation.

\section{Treatment and Posttreatment Course}

Conservative treatment in the form of medication for pain management and moderate activity as tolerated was recommended. At the 6-month follow-up, MRI demonstrated sustained resolution of the spinal cord herniation (Fig. 1E and F).

\section{Discussion}

Thoracic spinal cord herniation was first described in 1974 as a misdiagnosed and treatable cause of myelopathy, often presenting as a progressive Brown-Séquardlike syndrome. ${ }^{13}$ Since its first description, fewer than 200 cases have been reported in the literature. The disorder is characterized by anterior or anterolateral displacement of the spinal cord beyond the confines of the dural tube. There is only one reported case of dorsal thoracic spinal cord herniation. ${ }^{7}$ Consequent neurological deficits are thought to result from adhesion of the cord and vascular compromise. ${ }^{2}$ The condition primarily affects the thoracic spinal cord, frequently involving the T3-7 cord segments. ${ }^{4}$ Thoracic spinal cord herniation has been reported most commonly in middle-aged patients, at a mean age of 42 years, with a relative female predominance (male/female ratio $1: 1.8)^{3}$ The condition is often referred to as idiopathic as its etiology is unclear. Posited theories include congenital dural deficiency such as a preexisting ventral
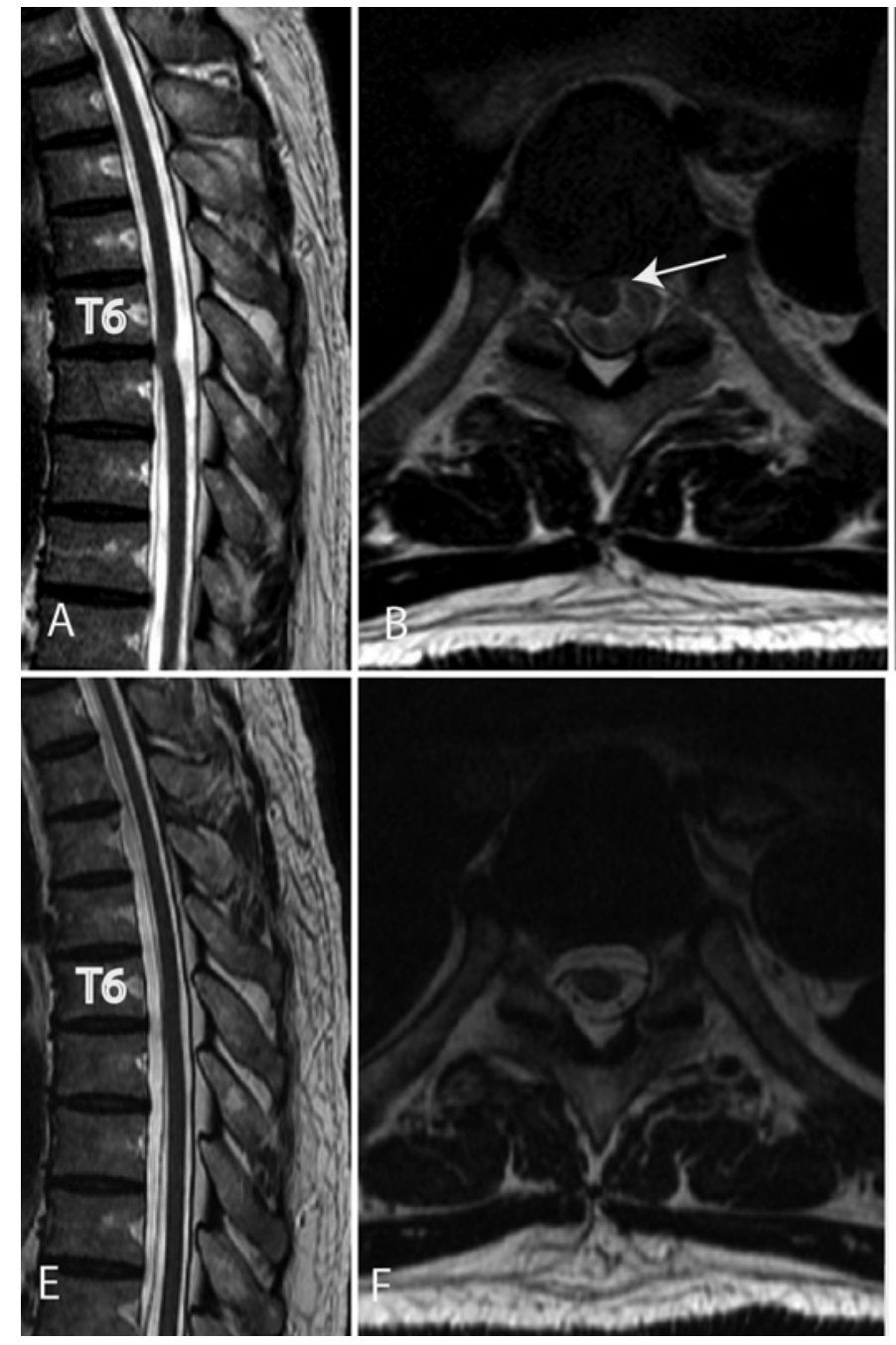
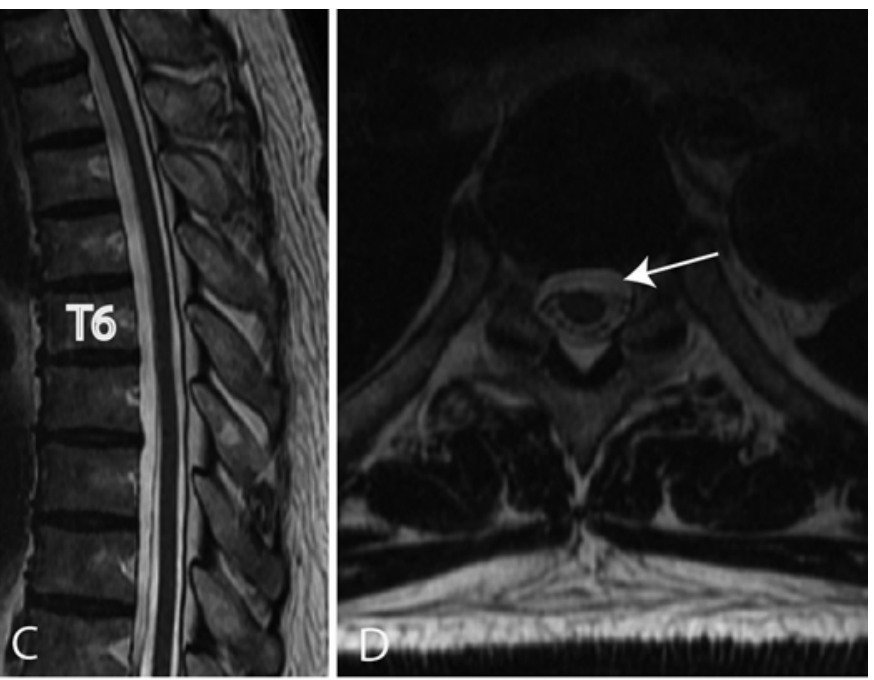

FIG. 1. A: Sagittal T2-weighted MR sequence revealing focal ventral displacement of the spinal cord characteristic of spinal cord herniation 1 year prior to presentation. B: Axial T2-weighted MR sequence demonstrating right anterolateral displacement of the spinal cord (arrow) at 1 year prior to presentation. C: Sagittal T2-weighted MR sequence obtained 1 month prior to presentation, demonstrating complete resolution of the spinal cord herniation. D: Axial T2-weighted MR sequence obtained 1 month prior to presentation, revealing the spinal cord within the dura and a probable ventral epidural CSF collection (arrow). E and F: Six-month follow-up sagittal and axial T2-weighted MR sequences demonstrating persistent resolution of the spinal cord herniation. 
meningocele, history of trauma, pressure erosion of the dura, and duplication of the ventral dura. ${ }^{9}$

Patients most commonly present with symptoms consistent with Brown-Séquard syndrome: contralateral diminished pain and temperature sensation and ipsilateral hemiparesis of the lower limb with spasticity and loss of proprioception. ${ }^{4}$ Prior to the mainstream use of MRI, spinal cord herniation was often misdiagnosed as a number of other conditions including multiple sclerosis, spinal cord atrophy, or intradural lesions. The condition is now preferentially diagnosed on the basis of MRI and should be distinguished from space-occupying CSF-isointense intraspinal extramedullary lesions such as epidermoid cysts or teratomas, epidural hematomas or abscesses, cystic nerve sheath tumors, synovial or Tarlov cysts, meningoceles, pseudomeningoceles, or intradural arachnoid cysts. ${ }^{5}$ Unimpeded CSF pulsation within a widened CSF space aids in excluding a space-occupying lesion. ${ }^{5}$ On axial MRI, nerve roots in the dorsal subarachnoid space are visible in spinal cord herniation, whereas nerve roots at the periphery of the cyst are visible in dorsal arachnoid cysts. ${ }^{12}$ Computed tomography myelography is an additional imaging modality that can be used to distinguish between spinal cord herniation and subarachnoid cysts as it allows visualization of the precise relationship of the spinal cord to the ventral dura. ${ }^{4}$

Surgical intervention with the intent of freeing the spinal cord and repairing the dural defect has been shown to stabilize or improve neurological symptoms. ${ }^{6}$ While operative treatment for spinal cord herniation has led to recovery or arrest in disease progression, cases of symptom recurrence following surgery have been reported. ${ }^{8,10}$ In a series of 12 patients with spinal cord herniation, $50 \%$ of the patients attained postoperative clinical improvement; however, a more recent review of 159 cases in the literature suggested a symptom improvement rate of $74 \%$ of patients. ${ }^{12}$ Although the majority of studies have reported favorable outcomes in patients with spinal cord herniation syndromes, long-term follow-up of surgically managed patients is warranted to assess postoperative course and complications such as the recurrence of ventral cord tethering, concentric scarring, and cord swelling, which have been documented in a number of studies. ${ }^{1}$ In cases where the condition is not clinically or radiologically progressive, conservative management has been encouraged. ${ }^{1}$

Presently, no evidence-based guidelines on the optimal treatment modalities for spinal cord herniation exist, and patient management has been largely individualized. ${ }^{12} \mathrm{Al}-$ though the majority of patients are treated with surgical measures, precise predictive algorithms to identify patients who would benefit from surgery are lacking. ${ }^{11}$ As this is the first reported case of spontaneously resolved spinal cord herniation, the incidence of this stable reversion cannot be estimated. For the featured patient, longterm follow-up will be necessary to monitor for potential herniation recurrence. However, this remarkable case illustrates the variability of this poorly understood clinical entity. Once a diagnosis of spinal cord herniation is made in patients without progressive clinical symptoms, conser- vative management appears favorable. Long-term followup of all patients with spinal cord herniation is warranted and highly encouraged and may contribute novel insight into the unknown natural history of this disease.

\section{References}

1. Ammar KN, Pritchard PR, Matz PG, Hadley MN: Spontaneous thoracic spinal cord herniation: three cases with longterm follow-up. Neurosurgery 57:E1067, 2005

2. Borges LF, Zervas NT, Lehrich JR: Idiopathic spinal cord herniation: a treatable cause of the Brown-Sequard syndrome-case report. Neurosurgery 36:1028-1033, 1995

3. Darbar A, Krishnamurthy S, Holsapple JW, Hodge CJ Jr: Ventral thoracic spinal cord herniation: frequently misdiagnosed entity. Spine (Phila Pa 1976) 31:E600-E605, 2006

4. Groen RJ, Middel B, Meilof JF, de Vos-van de Biezenbos JB, Enting RH, Coppes MH, et al: Operative treatment of anterior thoracic spinal cord herniation: three new cases and an individual patient data meta-analysis of 126 case reports. Neurosurgery 64 (3 Suppl):ons145-ons160, 2009

5. Haber MD, Nguyen DD, Li S: Differentiation of idiopathic spinal cord herniation from CSF-isointense intraspinal extramedullary lesions displacing the cord. Radiographics 34:313-329, 2014

6. Hassler W, Al-Kahlout E, Schick U: Spontaneous herniation of the spinal cord: operative technique and follow-up in 10 cases. J Neurosurg Spine 9:438-443, 2008

7. Le TC, Grunch BH, Karikari IO, Mehta AI, Owens TR, Gottfried ON, et al: Dorsal thoracic spinal cord herniation: report of an unusual case and review of the literature. Spine J 12:e9-e12, 2012

8. Massicotte EM, Montanera W, Ross Fleming JF, Tucker WS, Willinsky R, TerBrugge K, et al: Idiopathic spinal cord herniation: report of eight cases and review of the literature. Spine (Phila Pa 1976) 27:E233-E241, 2002

9. Morley S, Naidoo P, Robertson A, Chong W: Thoracic ventral dural defect: idiopathic spinal cord herniation. Australas Radiol 50:168-170, 2006

10. Selviaridis P, Balogiannis I, Foroglou N, Hatzisotiriou A, Patsalas I: Spontaneous spinal cord herniation: recurrence after 10 years. Spine J 9:e17-e19, 2009

11. Shin JH, Krishnaney AA: Idiopathic ventral spinal cord herniation: a rare presentation of tethered cord. Neurosurg Focus 29(1):E10, 2010

12. Summers JC, Balasubramani YV, Chan PC, Rosenfeld JV: Idiopathic spinal cord herniation: Clinical review and report of three cases. Asian J Neurosurg 8:97-105, 2013

13. Wortzman G, Tasker RR, Rewcastle NB, Richardson JC, Pearson FG: Spontaneous incarcerated herniation of the spinal cord into a vertebral body: a unique cause of paraplegia. Case report. J Neurosurg 41:631-635, 1974

\section{Author Contributions}

Acquisition of data: Samuel, Goldstein, Santaguida. Analysis and interpretation of data: Santaguida. Drafting the article: all authors. Critically revising the article: all authors. Reviewed submitted version of manuscript: Fehlings, Samuel. Approved the final version of the manuscript on behalf of all authors: Fehlings.

\section{Correspondence}

Michael G. Fehlings, Toronto Western Hospital, West Wing, 4th Fl., Rm. 4WW449, 399 Bathurst St., Toronto, ON M5T 2S8, Canada. email: michael.fehlings@uhn.on.ca. 